\title{
Effect of Cold Working and Long-Term Heating in Air on the Stress Corrosion Cracking Growth Rate in Commercial TT Alloy 690 Exposed to Simulated PWR Primary Water
}

\author{
TOSHIO YONEZAWA and ATSUSHI HASHIMOTO
}

\begin{abstract}
The authors have previously reported that the number of cavities at or near grain boundary (GB) carbides in commercial thermally treated (TT) Alloy 690 increases with increasing cold work reduction ratio and with heating temperature in air. In the present work after very long-term heating in air, the number of cavities at or near GB carbides in cold worked commercial TT Alloy 690 was observed to saturate, and the shape and size of the cavities changed. The shape and size of cavities and cracks were categorized, and a GB defect index number was defined as a function of their number, shape and size. Stress corrosion cracking growth rates in a commercial TT Alloy 690 with various levels of cold work exposed to simulated PWR primary water at $633 \mathrm{~K}\left(360{ }^{\circ} \mathrm{C}\right)$ have been measured and correlated with the defined GB defect index number. Cavities and cracks in the same materials before and after long-term heating in air have also been correlated with the defined GB defect index number. For the heavily cold worked ( $\geq 15 \mathrm{pct}$ ) commercial TT Alloy 690, a good correlation has been observed between the PWSCCGR and the GB defect index number. By contrast, for lightly cold worked ( $\leq 10 \mathrm{pct})$ commercial TT Alloy 690, the SCCGR in the simulated PWR primary water was very low and the GB defect index number was usually zero, regardless of cold working reduction ratio $\leq 10$ pct. It is concluded that the mechanism of SCCGR for lightly cold worked TT Alloy 690 in PWR primary water is likely to be different from that for heavily cold worked TT Alloy 690.
\end{abstract}

https://doi.org/10.1007/s11661-021-06286-6

(C) The Author(s) 2021

\section{INTRODUCTION}

Alloy 690 was developed about 50 years ago by the International Nickel Company as a corrosion resistant Nickel based $30 \mathrm{Cr}-9 \mathrm{Fe}$ alloy for many demanding high temperature environments. ${ }^{[1]}$ For application as a steam generator (SG) tube material in Pressurized Water Reactors (PWRs) as an alternative to mill annealed (MA) Alloy 600 (Ni based $15 \mathrm{Cr}-9 \mathrm{Fe}$ alloy), a high-temperature, fully solution heat treated (SHT) and thermally treated (TT) Alloy 690 was originally developed about 37 years ago by the first author of this paper together with his then colleagues from Mitsubishi Heavy Industries, Ltd. and Sumitomo Metal Industries, Ltd. (now Nippon Steel

TOSHIO YONEZAWA is with the Tohoku University, Sendai City 980-8579, Japan. Contact e-mail: toshio.yonezawa.d8@tohoku.ac.jp ATSUSHI HASHIMOTO is with the Kobe Material Testing Lab. Co., Ltd., Kako-gun, Harima 675-0155, Japan.

Manuscript submitted December 11, 2020; accepted April 4, 2021.

Article published online May 27, 2021
Corporation). ${ }^{[2,3]}$ This development of TT Alloy 690 depends on controlling combinations between the fully SHT and TT conditions as a function of carbon content that are selected to generate an optimized microstructure, as revealed by transmission electron microscopy (TEM) ${ }^{[4,5]}$ This TT Alloy 690 has excellent stress corrosion cracking (SCC) resistance in not only concentrated secondary water SG crevice environments but also in PWR primary water environments. It has been widely used as the alternative material to MA Alloy 600 not only for PWR SG tubes, but also for various PWR primary circuit pressure boundary components exposed to the primary water environment. TT Alloy 690 has now been used for more than 30 years in PWR primary water environments without any known SCC indications anywhere in the world. ${ }^{[6]}$

On the other hand, from the viewpoint of why the SCC can occur in the MA Alloy 600, the mechanism of the SCC for Ni-based alloys in the simulated PWR primary water has been discussed during more than 40 years. 
That is, aspects of the mechanism have been described from the viewpoints of microstructure, electrochemistry, Hydrogen embrittlement, slip dissolution mechanism, the internal oxidation mechanism etc. ${ }^{[7-26]}$

And many researchers have found that the TT Alloy 690 has excellent SCC resistance in the simulated PWR primary water.

By contrast, laboratory investigations by Paraventi and Moshier ${ }^{[27]}$ and by Arioka et al. ${ }^{[28]}$ have reported high values of PWR primary water SCC growth rates (PWSCCGR) in heavily cold worked TT Alloy 690 that were only a factor of about 5 to 10 times lower than those observed in cold worked MA Alloy 600 at similar yield strengths. In addition, Arioka et al. ${ }^{[28]}$ reported that cracked carbides, cavities and pores were observed at GBs in PWSCC susceptible, heavily cold worked TT Alloy 690. [28]

However, from the present authors' previous study, ${ }^{[29]}$ it was concluded that PWSCCGRs in heavily ( $\geq 15 \mathrm{pct}$ ) cold worked, laboratory melted heats of TT Alloy 690 depended on the particular heat and fabrication process examined. Moreover, cracks or cavities at or near eutectic $\mathrm{M}_{23} \mathrm{C}_{6}$ primary $\mathrm{GB}$ carbides were already observed immediately after cold working. By contrast, in the cold worked commercial TT Alloy 690, eutectic $\mathrm{M}_{23} \mathrm{C}_{6}$ primary $\mathrm{GB}$ carbides were hardly ever observed and the GB carbides were mostly secondary GB carbides precipitated during TT. After cold working, cavities at or near secondary GB carbides were detected even in the commercial TT Alloy 690. However, the number of such cavities at or near secondary GB carbides for the commercial TT Alloy 690 was very much smaller than the number of the cavities at or near eutectic $\mathrm{M}_{23} \mathrm{C}_{6}$ primary $\mathrm{GB}$ carbides and also secondary GB carbides in the laboratory melted and cold worked TT Alloy 690.

The authors deduced that the GB carbides in the TT Alloy 690 used by Arioka et al., and by Paraventi et al., were mainly retained eutectic primary $\mathrm{M}_{23} \mathrm{C}_{6}$ carbides resulting from industrially unrepresentative casting and hot working procedures, and that the high PWSCCGRs of their heats of TT Alloy 690 therefore depended on the presence of cracks and cavities at or near these eutectic primary $\mathrm{M}_{23} \mathrm{C}_{6}$ carbides. Thus, the PWSCCGRs for their cold worked heats of TT Alloy 690 were much larger than those for the authors' commercial heats of TT Alloy 690. ${ }^{[29]}$

In addition, Arioka et al. reported that voids and cavities were observed at or near grain boundaries (GBs) in zones in front of the PWSCC tip after long-term exposure in simulated PWR primary water at 633 $K{ }^{[30,31]}$ The authors of these papers ${ }^{[30,31]}$ proposed that the crack embryos originating from the coalescence of vacancies induced by cold work absorbed hydrogen and played an important role in the process of crack growth, both of PWSCC and of creep crack growth in cold worked TT Alloy 690 and cold worked MA Alloy 600 and even in cold worked carbon steel in high temperature water. Bruemmer et al. have also reported that cavities were observed in uniaxial tensile type SCC specimens of heavily cold forged commercial TT Alloy 690 after long-term exposure in simulated PWR primary water. On the basis of these data, Bruemmer et al. supported the creep damage hypothesis proposed by Arioka et al. ${ }^{[32-34]}$

If PWSCCGR in heavily cold worked TT Alloy 690 can be caused by creep damage, then it is expected that the residual stress in heavily cold worked TT Alloy 690 must reduce due to creep relaxation. Since residual stress is the driving force of most in-service PWSCC (and SCC of industrial components in general), then creep relaxation would be expected to progressively reduce PWSCC susceptibility by eliminating the stress driving force. From this perspective, we conclude that the hypothesis that PWSCC growth in heavily cold worked TT Alloy 690 is caused by the creep damage is not a sustainable hypothesis.

Moreover, to verify the involvement of "the creep damage hypothesis" as the mechanism of PWSCC, it is essential to show that it is not only a necessary condition but also a sufficient condition. Thus, not only must cavities be detected after a PWSCC test, but they should also exhibit the same stress dependency. The hypothesis of Arioka et al., is based on the observation of cavities in the specimens only after PWSCC tests and not on observations of the specimens before the PWSCC tests. It is also noted that in the paper by Bruemmer et al., no observations of cavities in the cold worked specimens are reported before the SCC tests.

In the present study, in order to examine the possibility of the creep driven mechanism of PWSCC in heavily cold worked commercial TT Alloy 690, the stress dependency of the number, shape and size of cavities at or near GB carbides was evaluated using three point bent beam SCC specimens and reverse U-bend SCC specimens before and after long-term exposure at $633 \mathrm{~K}$ to simulated PWR primary water. Additionally, to try to clarify the mechanism of PWSCCGR in cold worked commercial TT Alloy 690 with various levels of cold work, the PWSCCGR in simulated PWR primary water and the number, shape and size of the cavities at or near GB carbides were measured. The number, shape and size of the cavities at or near GB carbides in specimens of the cold worked commercial TT Alloy 690 were also observed before and after long-term heating in air as well as before and after long-term exposure in simulated PWR primary water at $633 \mathrm{~K}$.

\section{EXPERIMENTAL PROCEDURES}

\section{A. Materials}

One heat of commercial TT Alloy 690 pipe originally procured for industrial use as a PWR control rod drive mechanism (CRDM) nozzle and a re-solution heat treated (Re-SHT) Alloy 690 of the same heat were used in this study. The chemical composition by ladle analysis of the test material is shown in Table I. This commercial TT Alloy 690 was fabricated by a 60 ton vacuum oxygen decarburization, electro slag re-melting and hot extrusion processes and was finally thermally treated (TT) at $973 \mathrm{~K}$ for $54 \mathrm{ks}$ (15 hours) after SHT at $1,348 \mathrm{~K}$ for 3.6 
Table I. Chemical Composition and Heat Treatment for the Test Materials

\begin{tabular}{|c|c|c|c|c|c|c|c|c|c|c|}
\hline \multirow[b]{2}{*}{ Features } & \multicolumn{9}{|c|}{ Chemical Compositions by Ladle Analyses (Wt Pct) } & \multirow[b]{2}{*}{ Heat Treatment } \\
\hline & $\mathrm{C}$ & $\mathrm{Si}$ & $\mathrm{Mn}$ & $\mathrm{P}$ & $\mathrm{S}$ & $\mathrm{Ni}$ & $\mathrm{Cr}$ & $\mathrm{Ti}$ & $\mathrm{Fe}$ & \\
\hline $\begin{array}{l}\text { Commercial Heat TT Alloy } 690 \\
\text { Re-Solution Heat Treated for Commercial } \\
\text { Heat TT Alloy } 690\end{array}$ & 0.020 & 0.25 & 0.29 & 0.008 & 0.002 & 59.39 & 29.80 & 0.21 & 9.88 & $\begin{array}{l}\mathrm{SHT}(1)+\mathrm{TT} \\
\mathrm{SHT}(1)+\mathrm{TT}+\mathrm{SHT}(2)\end{array}$ \\
\hline
\end{tabular}

ks (1 hour). The Re-SHT Alloy 690 heat was finally SHT in the laboratory at $1,373 \mathrm{~K}$ for $3.6 \mathrm{ks}$ (1 hour).

The test materials were prepared by one-directional cold rolling to 5 or 10 pet or 15 or 20 pet or 30 pet reduction of $25 \mathrm{~mm}$ thick slabs machined from the commercial TT Alloy 690 CRDM nozzle material. The Re-SHT was carried out on $25 \mathrm{~mm}$ thick slabs machined from the commercial TT Alloy 690 CRDM nozzle. One of the Re-SHT $25 \mathrm{~mm}$ thick slabs was subsequently subjected to one-directional cold rolling to $15 \mathrm{pct}$ reduction.

One directional cold rolling was conducted by multiple passes of $\sim 50$ or 100 times, due to the relatively low load capacity of the 500 ton press available.

\section{B. Long-Term Heating in Air}

To evaluate the effect of heating time in PWR primary water up to the end of the estimated PWR plant lifetime and its effect on PWSCCGR and other metallurgical properties, long-term heating in air was conducted on the 0 to 30 pet cold rolled TT Alloy 690. Many test coupons in the form of $25 \mathrm{~mm}$ thick, $40 \mathrm{~mm}$ wide, $50 \mathrm{~mm}$ long were machined for this purpose from the 0 to 30 pet cold rolled TT Alloy 690 slabs. These test coupons were heated in air at 633 , or 673 , or $693 \mathrm{~K}$ for about 21.6 or 36 or 57.6 or 72 Ms (about 6,000 or 10,000 or 16,000 or 20,000 hours) or at $748 \mathrm{~K}$ for about 7.2 or 21.6 Ms (about 2,000 or 6,000 hours) and then water cooled. From these test coupons, CT test specimens for PWSCCGR test, Vickers hardness measurement test specimen, etc., were machined. SEM test specimens were cut from the above test specimens. The electric furnace for long-term heating in air controlled the temperature to within $\pm 1 \mathrm{~K}$. The heating time of $72 \mathrm{Ms}(20,000$ hours) at $693 \mathrm{~K}$ in air is equivalent to about $2,600 \mathrm{Ms}$ (about 80 years) at a PWR hot-leg operating temperature of $598 \mathrm{~K}$ for an activation energy estimated to be $130 \mathrm{~kJ} / \mathrm{mol}$. Considering the typical annual operating availability of PWRs, it is equivalent to more than 100 calendar years.

\section{PWSCC Test and Crack Growth Rate Measurement Test}

$0.7 \mathrm{~T}$ compact tension-type (CT) specimens with side grooves in the $\mathrm{T}-\mathrm{L}$ orientation to the cold rolling direction (RD) were selected for the PWSCCGR measurement tests; the susceptibility of $\mathrm{T}-\mathrm{L}$ orientation is directly related to the likely PWSCC propagation direction in practical components. These CT specimens were machined from the 15 or 20 or 30 pct one directionally cold rolled plates of the TT Alloy 690 or the 15 pct one directionally cold rolled plates of the Re-SHT Alloy 690.

The CT specimens were fatigue pre-cracked in air using sine wave loading at $30 \mathrm{~Hz}$ and a $K_{\max }$ value of 15 MPa $\sqrt{m}$ with a load ratio $\left(K_{\min } / K_{\max }\right) R \geq 0.3$.

After fatigue pre-cracking in air, the CT specimens were subjected to further in situ triangular wave fatigue pre-cracking at $633 \mathrm{~K}$ in simulated PWR primary water of composition 1,200 ppm B as $\mathrm{H}_{3} \mathrm{BO}_{3}, 3.0 \mathrm{ppm} \mathrm{Li}$ as $\mathrm{LiOH}$, dissolved oxygen $\leq 5 \mathrm{ppb}$, dissolved hydrogen $=$ $30 \mathrm{cc}(\mathrm{STP}) / \mathrm{kgH}_{2} \mathrm{O}$. An autoclave with a single axis loading rod incorporating 6 test specimens in series was used for the PWSCCGR measurements. The triangular wave loading for the in-situ fatigue pre-cracking was conducted in a series of steps: (1) $f=0.01 \mathrm{~Hz}, K_{\max } 30$ $\mathrm{MPa} \sqrt{\mathrm{m}}, R=0.3$, during $180 \mathrm{ks}$ (50 hours), (2) $f=0.01$ $\mathrm{Hz}, K_{\max } 30 \mathrm{MPa} \sqrt{\mathrm{m}}, R=0.5$, during $180 \mathrm{ks}$ (50 hours). After fatigue pre-cracking, a trapezoidal wave loading mode was applied as step (3) $f=0.0001 \mathrm{~Hz}$ (with stress increasing), $0.01 \mathrm{~Hz}$ (with stress decreasing), $K_{\max } 30$ $\mathrm{MPa} \sqrt{\mathrm{m}}, R=0.5$, holding time at $K_{\max } 30 \mathrm{MPa} \sqrt{\mathrm{m}}$ during $9 \mathrm{ks}$ (2.5 hours) to initiate inter-granular PWSCC (IGSCC). Step 3 was conducted during more than 7.2 Ms (2,000 hours). Subsequently, each specimen was held at a constant load at $13.89 \mathrm{kN}$ giving an initial crack tip $K$ value of $30 \mathrm{MPa} \sqrt{\mathrm{m}}$ during more than $7.2 \mathrm{Ms}(2,000$ hours).

The crack length in each specimen was continuously monitored by an in-situ direct potential drop technique linked to a data-logging system. All crack lengths were calibrated against the actual values measured on the fracture surfaces at the end of the test when the scheduled test time was completed.

After fractography, the Vickers hardness at $5 \mathrm{~kg}$ load was measured on a cross-section near the pre-fatigue crack of the CT specimens.

\section{Observations of Cracks and Cavities for Each Test Material by High-resolution SEM}

To evaluate the stress dependency of cavity formation, the number, shape and size of cavities at or near GB carbides were observed in 30 different zones of both stressed and stress-free areas of the three-point bent beam SCC test specimens made from 30 pct cold rolled 
commercial TT Alloy 690. In these cases, the applied tensile stress was $750 \mathrm{MPa}$ (as measured by X-ray diffraction) while exposed at $633 \mathrm{~K}$ in simulated PWR primary water for various exposure times 14.9, 22.7 and $30.7 \mathrm{Ms}(4,137,6,312$ and 8,532 hours). In addition, the number, shape and size of cavities at or near GB carbides were observed in 30 different zones at GBs both parallel to and orthogonal to the cold rolling direction (RD). These observations were made at the maximum stressed area of the reverse U-bend specimens made from 30 pet cold rolled commercial TT Alloy 690 both before and after exposure at $633 \mathrm{~K}$ in simulated PWR primary water for $36.4 \mathrm{Ms}$ (10,108 hours).

To evaluate the effect of cold working, long-term heating in air, and exposure time in simulated PWR primary water on cavity formation, a total 160 specimens were tested. These specimens were heated in air at 633 or 673 or 693 or $748 \mathrm{~K}$ during about 7.2 or 21.6 or 36 or $72 \mathrm{Ms}(2,000$ or 6,000 or 10,000 or 20,000 hours $)$ or exposed at $633 \mathrm{~K}$ in simulated PWR primary water with different hydrogen concentrations during $3.33 \mathrm{Ms}$ (925 hours). Cavity observations were made on every specimen before and after heating in air or exposure in simulated PWR primary water after the specimens had been polished by colloidal alumina followed by ion milling (Hitachi IM-4000). The number, shape and size of cavities at or near GB carbides in 30 different zones on each specimen without any applied stress was observed using high resolution scanning electron microscopy (SEM) : Hitachi SU-70 and FEI Helios Nano Lab Dual Beam 600i instruments) with a $15 \mathrm{kV}$ acceleration voltage, a column condition with a small probe-current mode and a high probe-current range, in order to obtain the required resolution of $1.0 \mathrm{~nm}$. In order to detect the tiny cavities and the relationship between the cavities and stripped pattern due to cold working, the SEM photos were intentionally taken using the electron channeling contrast.

The total number of observed zones by high resolution SEM was 4,800 (i.e. 30 observed zones $\times 160$ specimens). The dimensions of each zone for the high-resolution SEM observations was about $12 \times 9$ microns. Cavities at or near GB carbides were observed at 10,000 times magnification in each zone examined. The number, shape and size of cavities at or near GB carbides were counted on 4 times magnified photographs (taken at 10,000 times magnification) in each observed zone. The number, shape and size of cavities at or near GB carbides were therefore counted in a total of 4,800 zones at 40,000 times magnification.

Using the above various level of cold rolled commercial TT Alloy 690 after long-term heated in air, the effects of long-term heating in air on the Vickers hardness and PWSCCGR will be reported in the near future, as the next step of this study.

By the way, even in the Alloy 690, the amount of $\mathrm{Cr}$ carbide precipitation is depended on the amount of solute C content in the matrix. Since the TT Alloy 690 is subjected to Thermal Treatment (ageing) at $700{ }^{\circ} \mathrm{C}$ (973K) for 15 hours (in this study), the remained solute $\mathrm{C}$ content in the matrix and the possible amount of $\mathrm{Cr}$ $\mathrm{GB}$ carbide precipitation at $360{ }^{\circ} \mathrm{C}(533 \mathrm{~K})$ to $420{ }^{\circ} \mathrm{C}$ are higher than those at $475^{\circ} \mathrm{C}(748 \mathrm{~K})$. But, the diffusion rate and reaction rate at $360{ }^{\circ} \mathrm{C}$ to $420{ }^{\circ} \mathrm{C}$ are much lower than those at $475^{\circ} \mathrm{C}$. Therefore, in case of the heating at $360{ }^{\circ} \mathrm{C}$ to $420{ }^{\circ} \mathrm{C}$ even for long-term, the precipitation of the grain boundary carbides is not remarkable, and only agglomerate of the lattice defects and voids are detected. On the other hand, in case of heating at $475^{\circ} \mathrm{C}$ for a long-term, not only the agglomeration of lattice defects and voids but also the precipitation of the grain boundary $\mathrm{Cr}$ carbides is remarkable.

So, regarding the effect of heating in air on the microstructure for TT Alloy 690, this study focuses on the cavities near GB carbides and cracks of the GB carbides.

\section{TEST RESULTS AND DISCUSSION}

\section{A. Cavity Distributions At or Near GB Carbides vs GB Orientation Relative to the $R D$}

In order to better understand the mechanism of cavity formation for heavily cold rolled TT Alloy 690, the relationship between the number of cavities at or near GBs and carbides as a function of GB orientation to the RD had to be determined for each specimen.

Initially, during the process of counting the number of cavities at or near GB carbides, it was found that as the number of observed zones increased, the number of cavities at or near GB carbides was dependent on the orientation of GBs relative to the RD. Therefore, in order to clarify the orientation of GBs relative to the $\mathrm{RD}$, the observed surfaces were defined as $\mathrm{S}-\mathrm{T}$ or $\mathrm{S}-\mathrm{L}$ planes in relation to the cold rolling $\mathrm{T}-\mathrm{L}$ plane, as shown in Figure 1. The observed GB orientations parallel to the plate thickness or RD were defined, as shown in Figure 2(a), as "GBs parallel to or orthogonal to the plate thickness or RD". GBs designated parallel to or orthogonal to the plate thickness or RD were within about \pm 15 degrees relative to the exact parallel or orthogonal orientations.

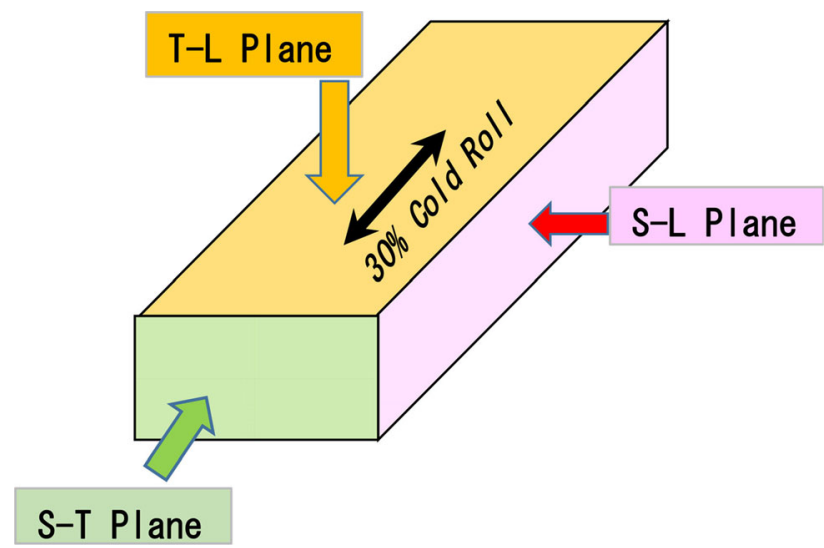

Fig. 1-Definition of the observation planes as T-L, S-T and S-L relative to the cold rolling direction (RD). 


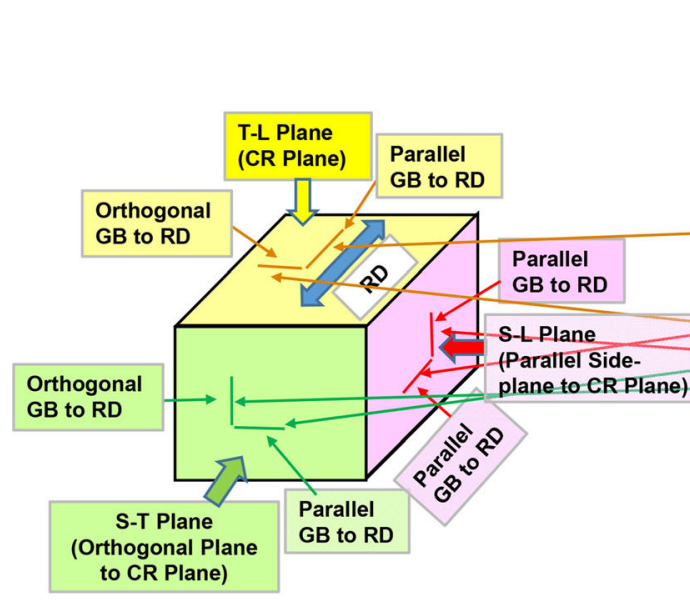

(a)

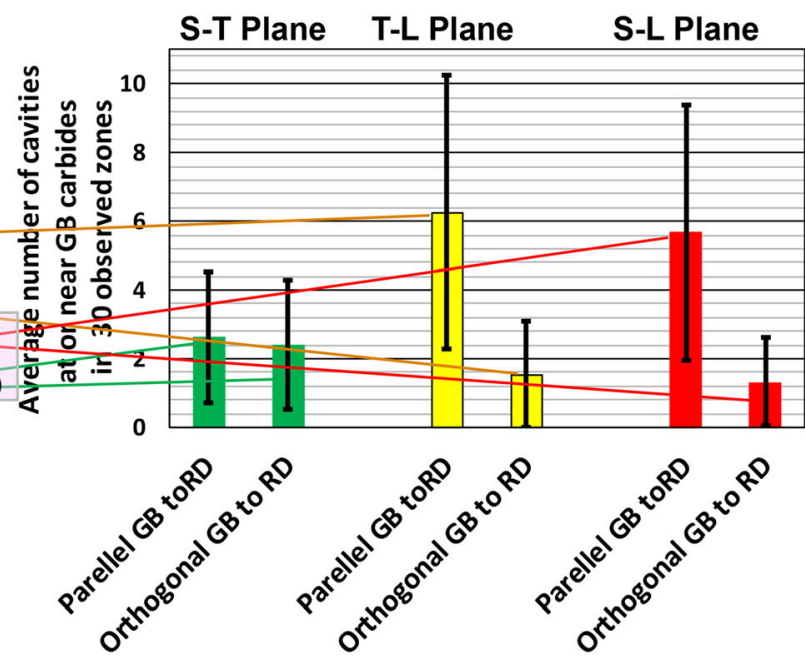

(b)

Fig. 2-(a) Observed GB orientations parallel to the plate thickness or RD defined as "GBs parallel to plate thickness or RD" or as "GBs orthogonal to plate thickness or RD". (b) Average number of the detected cavities at or near GB carbides with error bar of standard deviation in 30 observed zones on the observation plane and GB orientations for 30 pct cold rolled commercial TT Alloy 690.

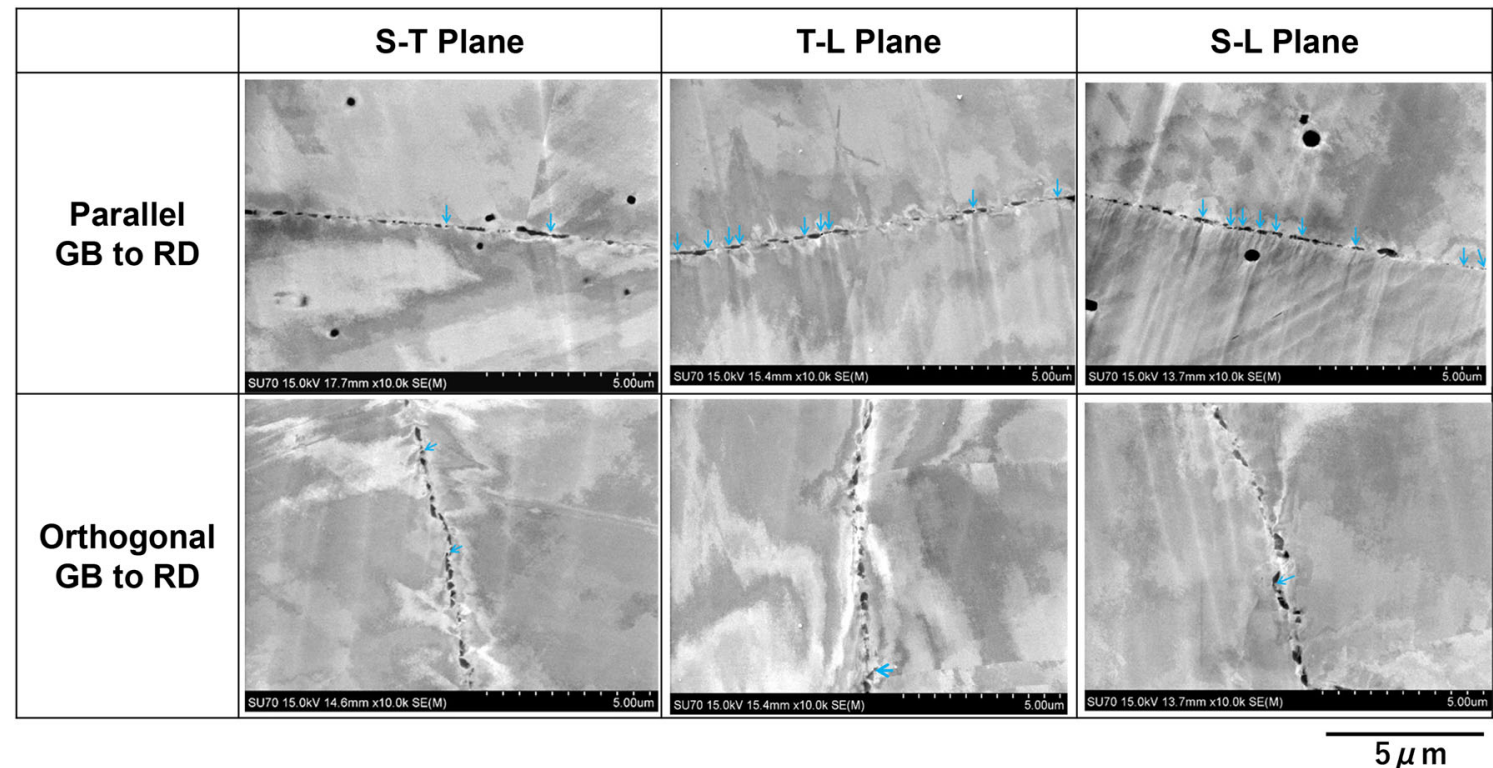

Fig. 3-Representative photographs of the cavities at or near GB carbides parallel to the plate thickness or RD or orthogonal to the plate thickness or RD for the T-L, S-T and S-L observation planes of 30 pct cold rolled commercial TT Alloy 690 before heating in air. (The detected cavities are indicated by blue arrows).

GBs parallel to or orthogonal to the plate thickness or RD were observed on the T-L, S-T and S-L planes before heating in air or before exposure to simulated PWR primary water. The average numbers of cavities at or near GB carbides according to these categories are shown in Figure 2(b)). Representative micrographs of the data given in Figure 2(b)) are shown in Figure 3. Locations where cavities were detected are indicated by blue arrows. From these figures, it is clear that the average number of cavities at or near GB carbides in each of the batches of 30 observed zones along GBs parallel to the RD in the T-L and $\mathrm{S}-\mathrm{L}$ planes is much larger compared to GBs orthogonal to the $\mathrm{RD}$.
However, in the S-T plane, both GBs parallel to and orthogonal to the plate thickness were observed to have almost the same number of cavities. In the T-L and $\mathrm{S}-\mathrm{L}$ planes, GBs parallel to the RD have the same parallel orientation relative to the RD but in the S-T plane GBs parallel and orthogonal to the plate thickness are both perpendicular to the RD. Thus, it can be seen that many cavities at or near GB carbides are always observed in GBs that are parallel to the RD.

From these observations, it is considered that as grains are compressed during cold rolling, the cavities are generated at or near GB carbides by the shear strain between adjacent grains. Furthermore, it is considered 
that the shear strain is large in parallel GBs but small in orthogonal GBs. Therefore, it seems that the difference in the number of cavities at or near GB carbides, depending on their orientation relative to the RD, is caused by differences in shear strain.

\section{B. Definition of the GB Defect Index Number}

The authors have reported in a previous paper ${ }^{[29]}$ the effect of cold rolling reduction ratio, heating at 673 and $748 \mathrm{~K}$ in air for about 7.2 Ms (2,000 hours) and exposure for 3.33 MS (925 hours) in simulated PWR primary water with two different Hydrogen concentrations on the average number of detected cavities at or near GB carbides in cold rolled commercial TT Alloy 690. They also reported the effect of cold rolling reduction ratio, heating at $748 \mathrm{~K}$ in air for about 7.2 Ms (2,000 hours) on the average number of detected cavities at or near GB carbides for the Re-SHT Alloy 690. These data are shown in Figure 4, from which the authors estimated that the number of cavities at or near GB carbides for cold rolled commercial TT Alloy 690 increases with increasing cold rolling reduction ratio and temperature of heating in air. However, in case of the Re-SHT Alloy 690, cavities at or near GB carbides were not detected regardless of cold working or heating in air.

From the extensive additional observations reported here, and after further heating at 633 or $693 \mathrm{~K}$ for about $72 \mathrm{Ms}(20,000$ hours $)$ or at $748 \mathrm{~K}$ during $22.82 \mathrm{Ms}$ (6,340 hours) in air, it can no longer be claimed that the number of cavities at or near GB carbides in cold rolled commercial TT Alloy 690 increases with increasing heating temperature, as shown by the new data in Figure 5. It was also observed that not only the number of cavities at or near GB carbides in cold rolled commercial TT Alloy 690 increased with the degree of cold work but also that their shape and size changed with increasing heating temperature and time, as shown by the example micrographs in Figure 6.
Consequently, in this study, the shape of cavities formed in cold worked commercial TT Alloy 690 were categorized according to cavity type and crack type. The sizes of each cavity and crack type were categorized as A to $\mathrm{D}$ and $\alpha$ to $\gamma$, respectively, according to their diameter or width, as shown in Figure 7 . By definition, the size categories of cavity types A, B, C and D are, respectively, $\leq 20 \mathrm{~nm}, 50 \mathrm{~nm}, 100 \mathrm{~nm}$ and $200 \mathrm{~nm}$ in diameter, and the crack width categories $\alpha, \beta$ and $\gamma$ are, respectively, $\leq 20 \mathrm{~nm}, 50 \mathrm{~nm}$ and $100 \mathrm{~nm}$ wide. According to this categorization scheme, the typical distributions of the numbers of cavities or cracks in each size type for 30 pct cold rolled TT Alloy 690 after different heating temperatures and times are shown in Figure 8. It is clear that the numbers of large cavities or crack types increase with increasing heating temperature in air.

Based on the defined categories A, B, C and D for cavity size types, the authors assigned coefficients 1, 3, 5 and 7 , respectively. Similarly, for the crack type categories $\alpha, \beta$ and $\gamma$, coefficients 2,4 and 6 , respectively, were assigned. Subsequently, the numbers of cavities in categories A, B, C and D were multiplied by the coefficients $1,3,5$ and 7 , respectively, and summed and designated $\sum 1$. Similarly, the number of cracks in categories $\alpha, \beta$ and $\gamma$ were multiplied by the coefficients 2,4 and 6 , respectively, and the sum designated $\sum 2$. The sum of $\sum 1$ and $\sum 2$ was then defined as the GB defect index number, as shown in Figure 7 and by the following equation:

$$
\begin{aligned}
& G B \text { defect index number }=\sum(\text { total number of } A \times 1 \\
& + \text { total number of } B \times 3+\text { total number of } C \times 5 \\
& + \text { total number of } D \times 7)+\sum(\text { total number of } \alpha \times 2 \\
& + \text { total number of } \beta \times 4+\text { total number of } \gamma \times 6)
\end{aligned}
$$

This GB defect index number was calculated for each observed zone, and calculated the average number and standard deviation of GB defect index in the 30 observed zone.

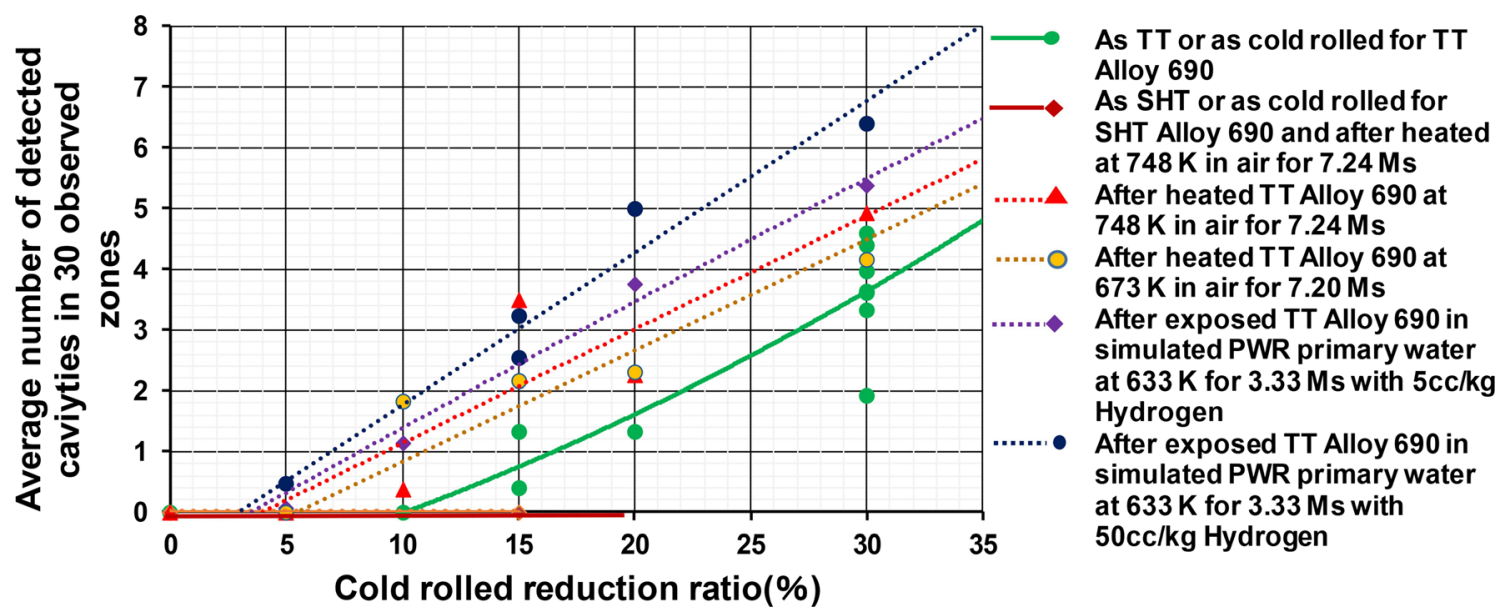

Fig. 4-The effect of cold rolling reduction ratio, heating at $748 \mathrm{~K}$ in air for about $7.2 \mathrm{Ms}(2,000 \mathrm{~h})$ or exposure at $633 \mathrm{~K}$ for $3.33 \mathrm{Ms}(925 \mathrm{~h})$ in simulated PWR primary water with different Hydrogen concentrations on the average number of detected cavities at or near GB carbides in 30 observed zones for the cold rolled commercial TT Alloy 690 and Re-SHT Alloy 690. ${ }^{[35]}$ All data in this figure were measured for stress free specimens. 


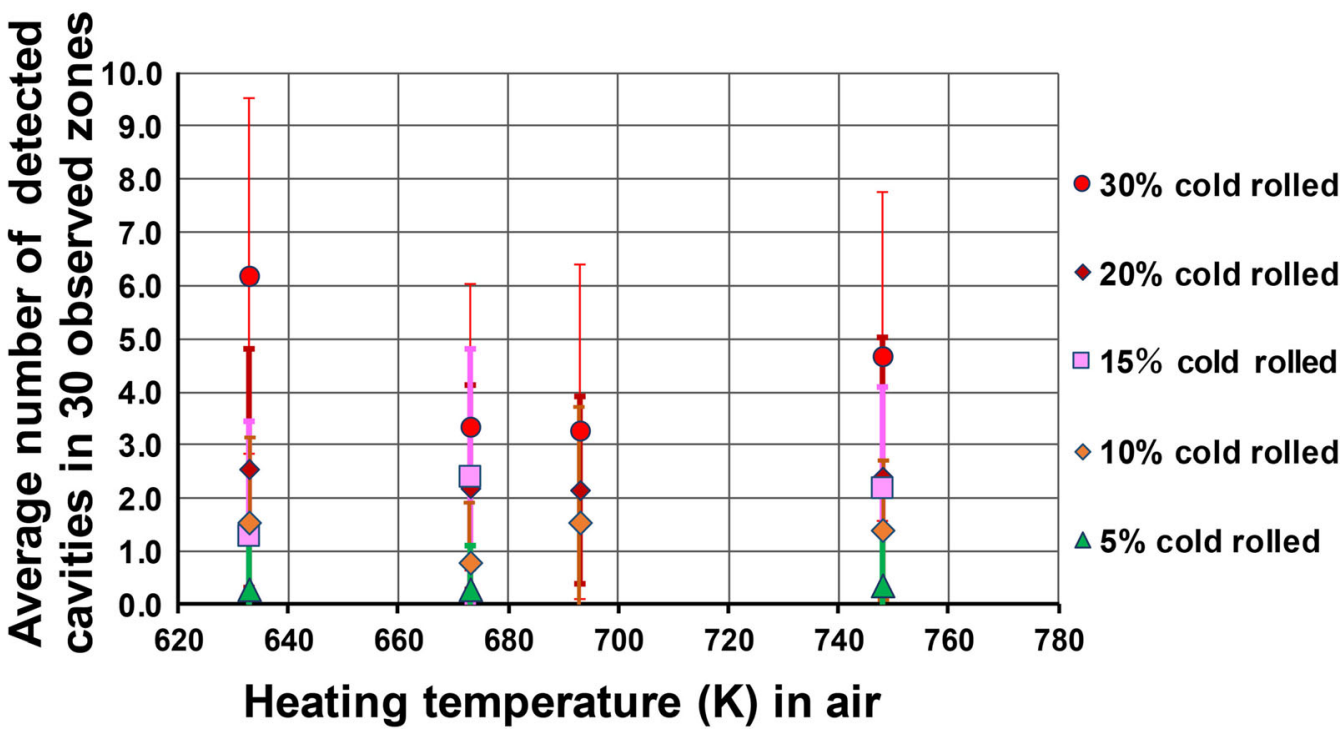

Fig. 5-The effect of cold rolling reduction ratio, heating temperature at 633 to $693 \mathrm{~K}$ during about $7.2 \mathrm{Ms}(2,000 \mathrm{~h})$ and $748 \mathrm{~K}$ during 22.82 Ms $(6,340 \mathrm{~h})$ in air on the average number of detected cavities at or near GB carbides in 30 observed zones with error bar of standard deviation for the cold rolled commercial TT Alloy 690.

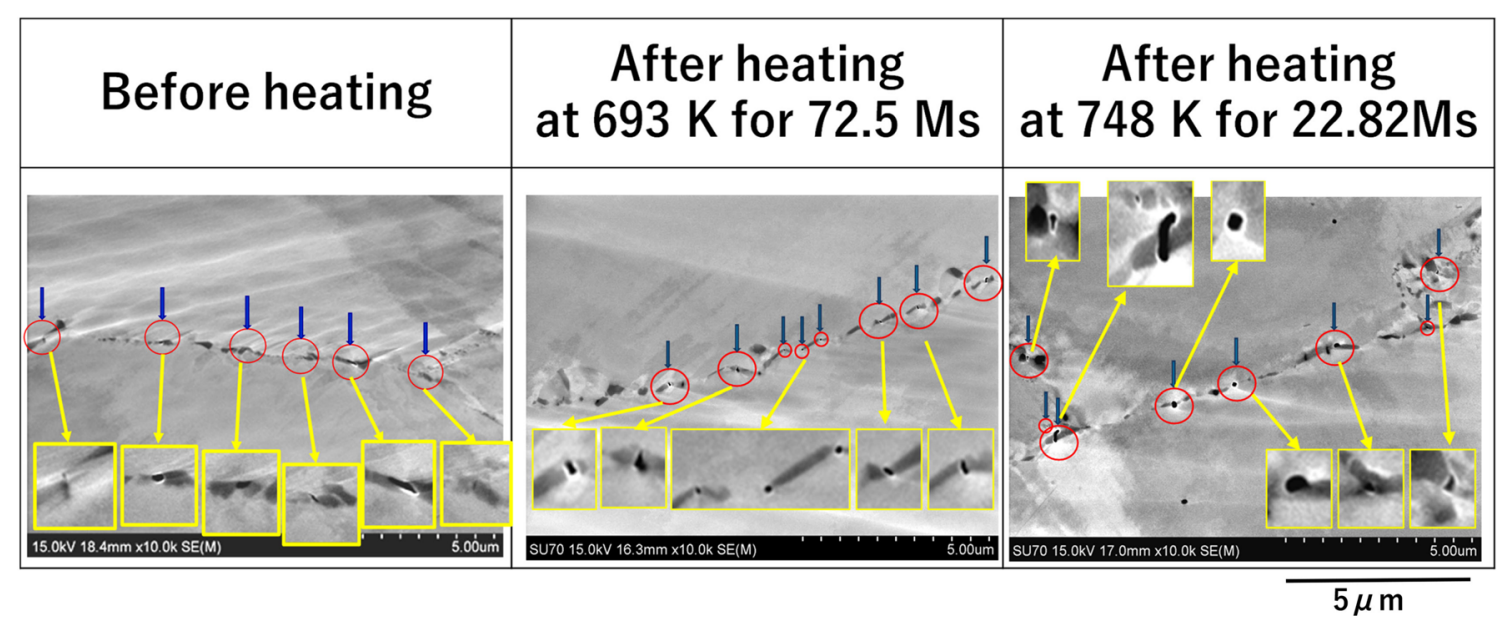

Fig. 6-Typical examples of the changes in shape and size of cavities at or near GB carbides after heating at $693 \mathrm{~K}$ during 72.5 Ms (20,142hours) and $748 \mathrm{~K}$ during $22.82 \mathrm{Ms}(6,340 \mathrm{~h})$ for 20 pct cold rolled commercial TT Alloy 690.

\section{Stress Dependency of the GB Defect Index Number}

Arioka et al. have reported that a high density of cavities was observed at grain boundaries ahead of PWSCC tips after long-term exposure at $633 \mathrm{~K}$ in simulated PWR primary water. They also reported that the cavities appeared to nucleate at or near intergranular carbides by condensation of vacancies at the crack tips of both PWSCC and creep cracks in cold rolled TT Alloy $690 .{ }^{[31]}$ They indicated that there is a similarity in the temperature dependence of crack growth rate between PWSCC and creep cracking for heavily cold rolled TT Alloy 690, leading them to hypothesize that the mechanism of PWSCC in heavily cold rolled TT Alloy 690 can be creep damage. ${ }^{[28,30,31]}$

However, as previously stated, to confirm the creep damage hypothesis as the precursor mechanism for IGSCC, it is necessary to prove that not only is creep a necessary condition but also a sufficient condition. In other words, it is necessary to show not only that the temperature dependency of crack growth rate and creep cavity formation are similar, but also that cavity formation and deformation have the same stress dependencies.

As reported previously, the effect of stress on cavity formation for the 30 pct cold rolled commercial TT Alloy 690 was tested using the three-point bent beam SCC test specimens. ${ }^{[35]}$ High resolution SEM photographs were taken of the stressed area and of a stress-free area for each of the three-point bent beam SCC specimens after exposure at $633 \mathrm{~K}$ in simulated PWR primary water during 14.9, 22.7 and $30.7 \mathrm{Ms}$ (4,137, 6,312 and 8,532 hours).

As shown in Figure 9, cavities at or near GB carbides were detected in not only the maximum tensile stressed 


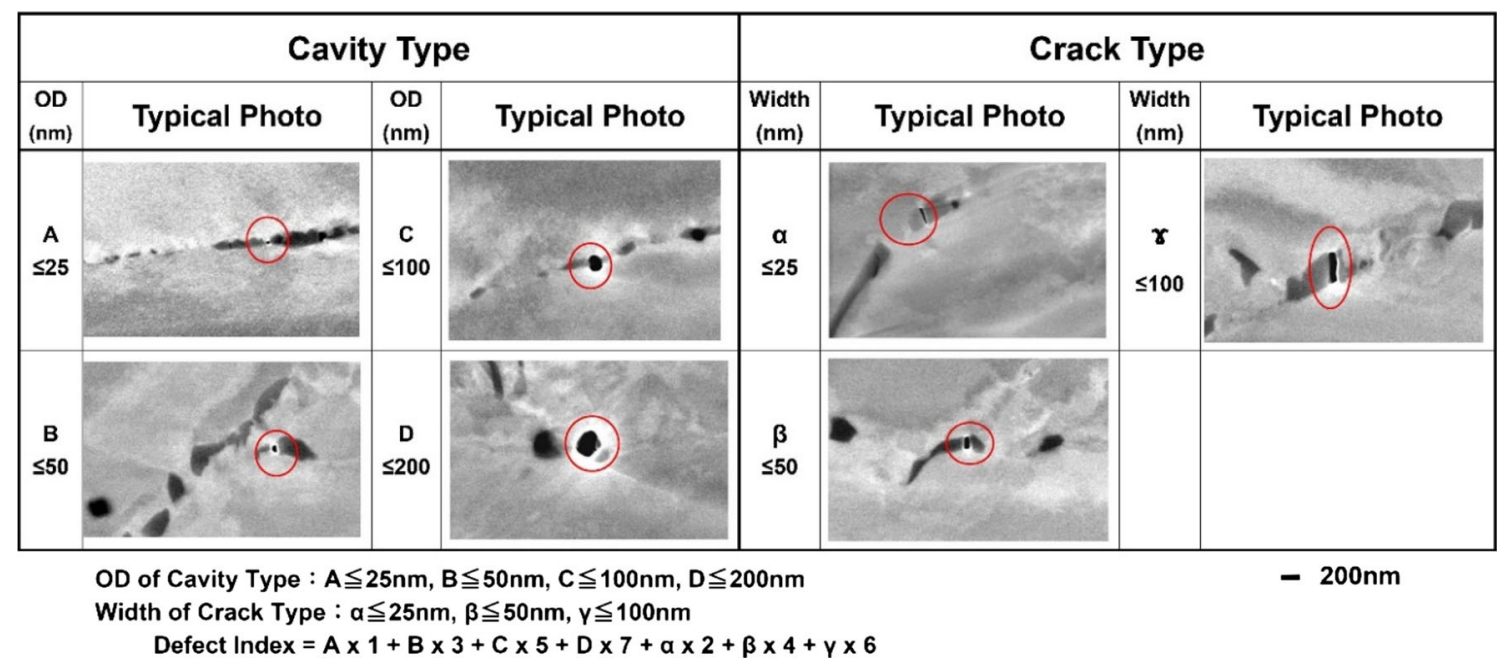

Fig. 7- Categorization of the shape and size of cavities at or near GB carbides for cold rolled commercial TT Alloy 690 where categories A to $\mathrm{D}$ are based on the diameter of cavities and categories $\alpha$ to $\gamma$ are based on the width of cracks that are usually transverse to the longest dimension of the carbides. The GB defect index number is defined as $A \times 1+B \times 3+C \times 5+D \times 7+\alpha \times 2+\beta \times 4+\gamma \times 6$.

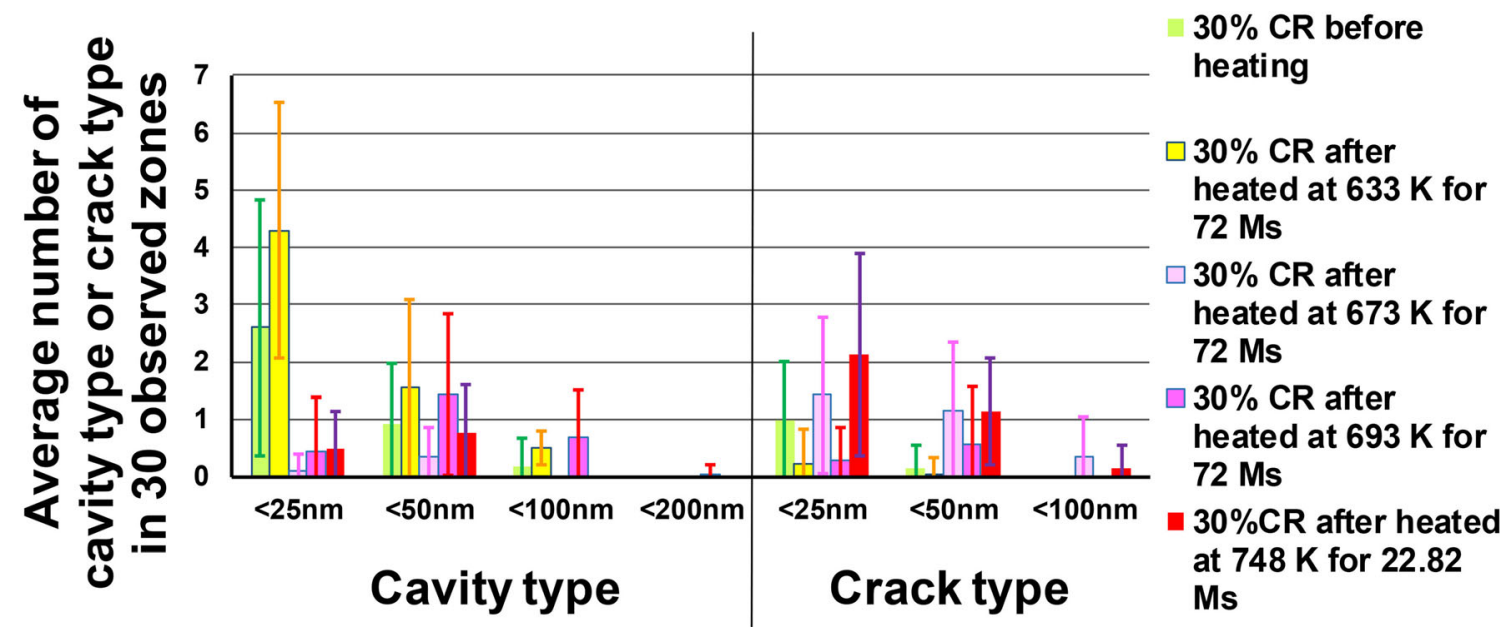

Fig. 8-Effect of heating temperature at 633 to $693 \mathrm{~K}$ for $72 \mathrm{Ms}(20,000 \mathrm{~h})$ or at $748 \mathrm{~K}$ for $22.82 \mathrm{Ms}(6,340 \mathrm{~h})$ on the cavity and crack types in 30 observed zones with error bar of standard deviation from the viewpoint of their diameter and width, respectively.

areas but also in the stress-free areas of three point bent beam SCC specimens. The observed cavities are quite similar in appearance to the "creep driven cavities" reported by Arioka et al.

The cavity observations previously reported for the 30 different zones of the maximum tensile stressed areas and stress-free areas of the 3-point bent beam specimens after three exposure times (14.9, 22.7 and $30.7 \mathrm{Ms}$ ) (4,137, 6,312 and 8,532 hours) in simulated PWR primary water were re-analyzed as a function of the GB defect index numbers, as shown in Figure 10. From this figure, it is clear that there is no difference in the GB defect index number between the maximum tensile stressed areas and the stress-free areas for the threepoint bent beam SCC test specimens after the three exposure times.

But, the three point bent beam specimens are not so easy to reproduce the PWSCC in the laboratory test due to relatively low residual stress. So, in addition, in this study, reverse U-bend specimens were additionally manufactured from the 30 pct cold rolled commercial TT Alloy 690 according to ISO/TC $156 \mathrm{~N} 1172^{[36]}$ and were exposed at $633 \mathrm{~K}$ in simulated PWR primary water during $36.4 \mathrm{Ms}(10,108$ hours). (A summary of the manufacturing procedure for the reverse U-bend specimens is illustrated in Figure 11.) High-resolution SEM BSE photos were taken of GBs parallel and orthogonal to the RD at the highest stressed peak of each reverse U-bend specimens before and after exposure and the GB defect index numbers were calculated and compared in Figure 11 (SEM BSE photos in Figure 11 were taken stressed specimen after exposure in simulated PWR primary water). It is well known that the applied tensile stress level at the top of $U$ bend area is substantially the same along the longitudinal and orthogonal axes of the specimens. (In Figure 11, the longitudinal axis is "parallel to the RD" and the orthogonal axis is "orthogonal to the RD".) However, the applied total strain in the 


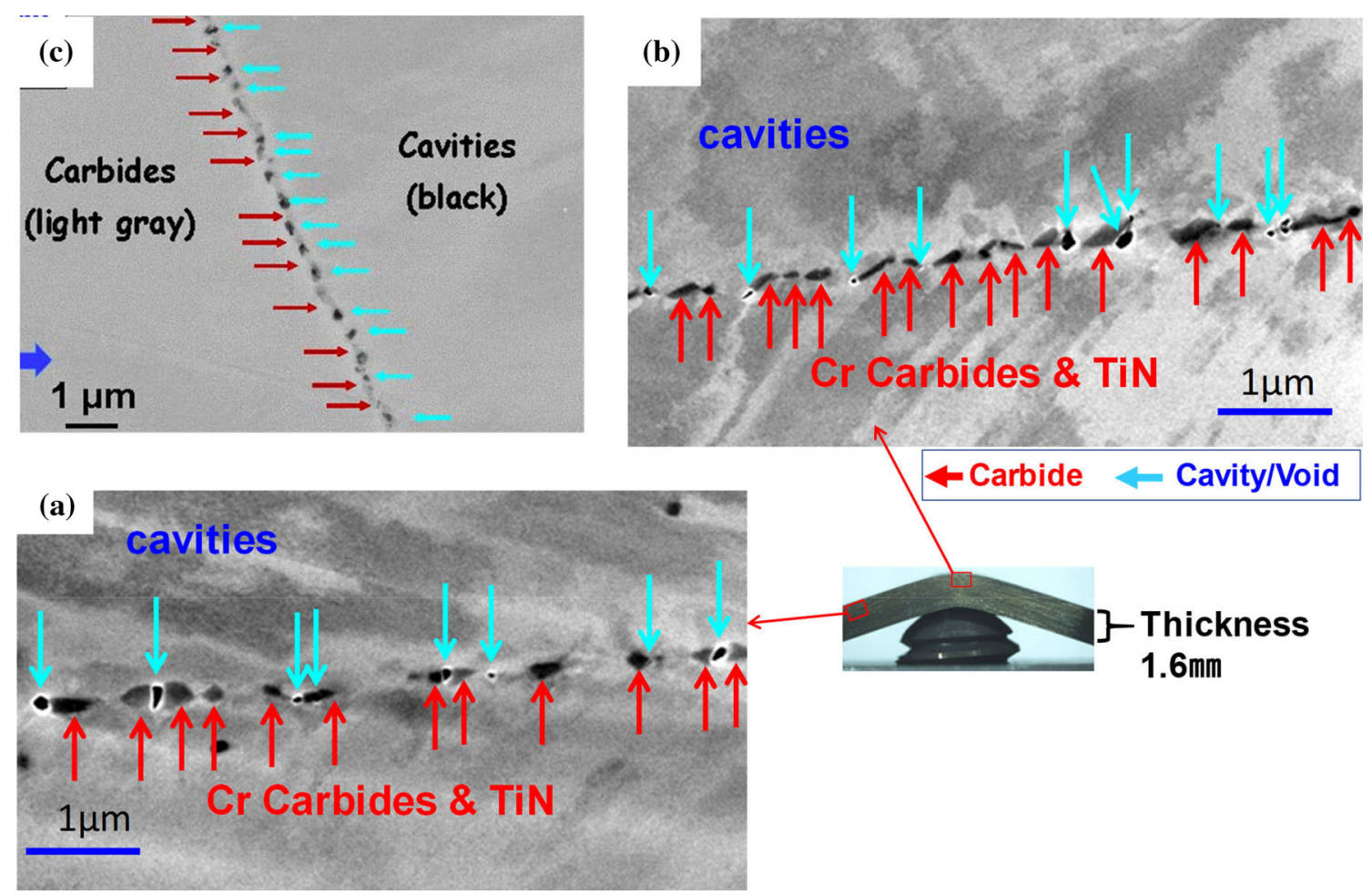

Fig. 9-Observed cavities at or near GB carbides in the stress-free area $(a)$ and maximum tensile stressed area $(b)$. The cavities reported by Arioka et al are shown in $(c)$.

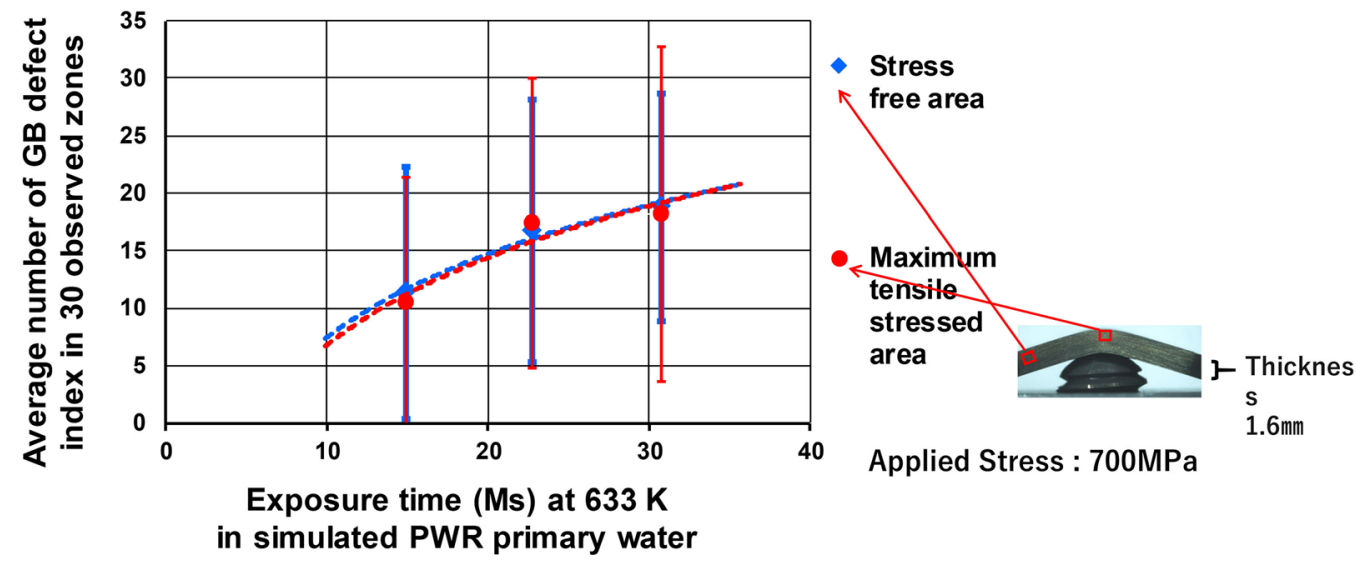

Fig. 10 - Comparison of the average number of GB defect index in 30 observed zones with error bar of standard deviation between the maximum tensile stressed area and a stress-free area for three point bent beam SCC specimens after various exposure times (14.9, 22.7 and 30.7 Ms) $(4,137,6,312$ and $8,532 \mathrm{~h})$ at $633 \mathrm{~K}$ in simulated PWR primary water.

orthogonal axis is slightly higher than that in the longitudinal axis.

As shown in Figure 11, the GB defect index number for GBs orthogonal to the RD is slightly larger than that for GBs parallel to the RD before and after exposure at $633 \mathrm{~K}$ in simulated PWR primary water for $36.4 \mathrm{Ms}$ (10,108 hours). The difference between the GB defect index numbers for GBs parallel and orthogonal to the
$\mathrm{RD}$ is thought to be due to the differences in total applied strain for these GB orientations relative to the RD.

From Figures 10 and 11, it is clear that there is no stress dependency for cavity formation for both the three-point bent beam SCC test specimens and reverse U-bend SCC test specimens. It is concluded, therefore, that the detected cavities for heavily cold rolled com- 


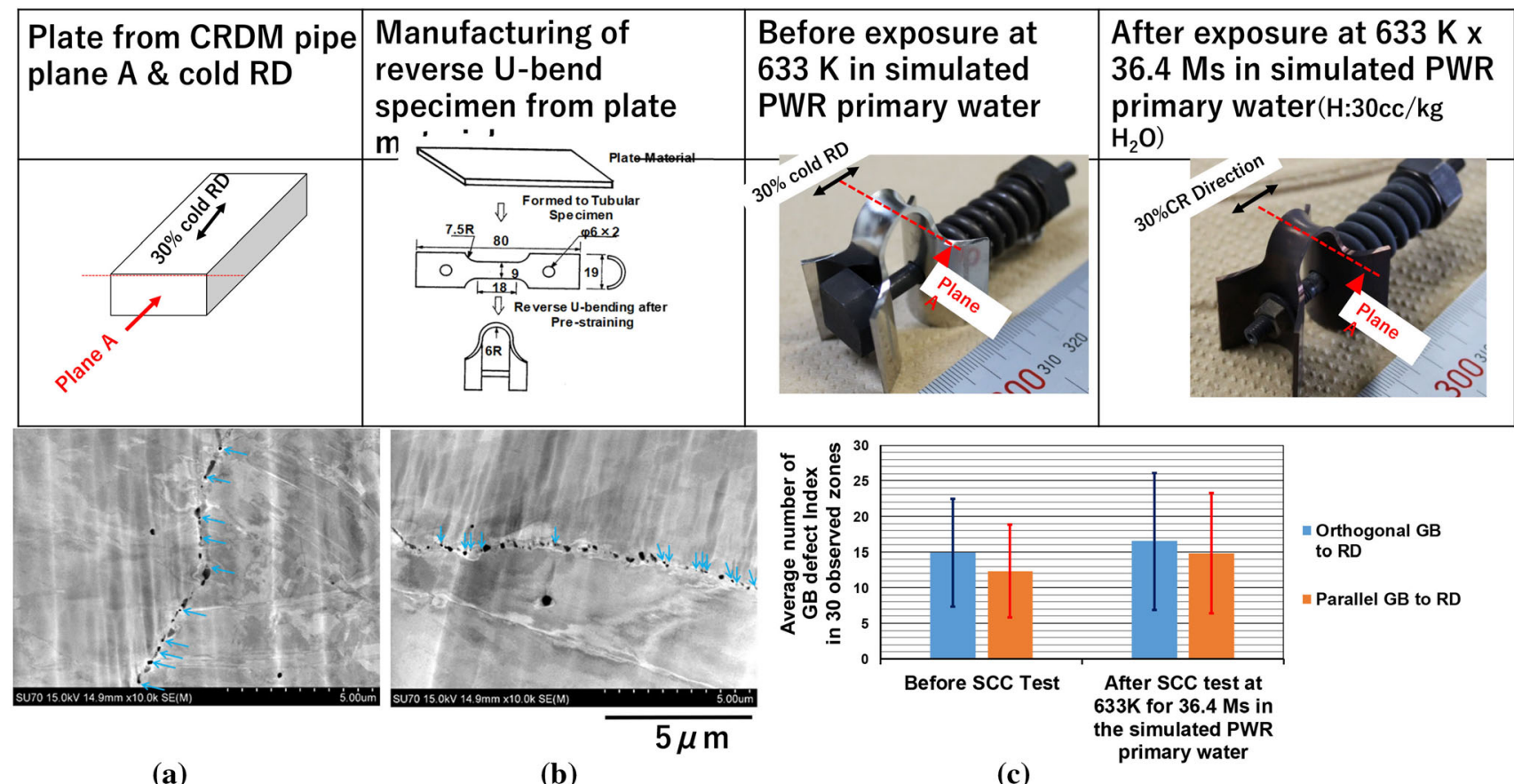

Fig. 11 - Comparison of the average number of GB defect index in 30 observed zones with error bar of standard deviation between GBs orthogonal to the RD and GBs parallel to the RD for the reverse U-bend specimens before and after exposure at $633 \mathrm{~K}$ in simulated PWR primary water during $36.4 \mathrm{Ms}(10,108 \mathrm{~h})$. (a) Typical photo of cavities at or near GBs orthogonal to the RD near the top of the U bend stressed area after SCC test, (b) typical photo of cavities at or near GBs parallel to the RD near the top of the U bend stressed area after SCC test, (c) comparison of GB defect index numbers between different orientations of GBs for reverse U bend SCC test specimen before and after exposure in simulated PWR primary water.

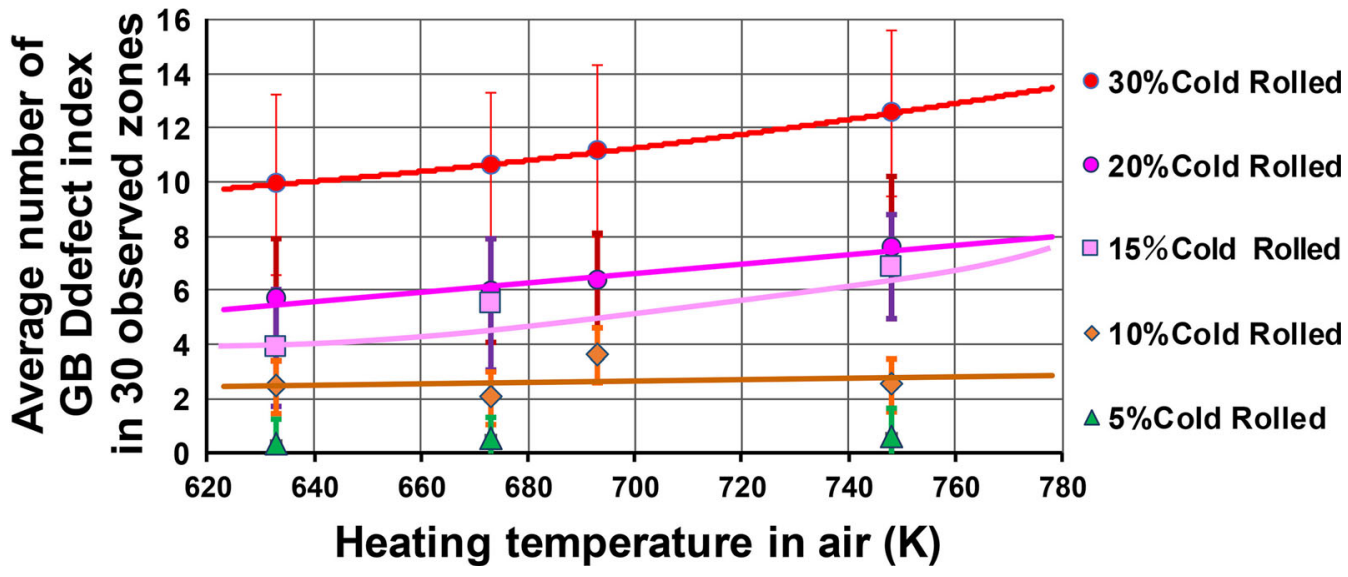

Fig. 12 - Change in the average number of GB defect index in 30 observed zones with error bar of standard deviation as a function of heating temperature in air and cold rolling reduction ratio.

mercial TT Alloy 690 after exposure in the simulated PWR primary water at $633 \mathrm{~K}$ are clearly not related to creep damage.

D. Effect of Long-Term Heating Temperature and Time in Air and of Exposure in the Simulated PWR Primary Water with Different Hydrogen Concentrations on the GB Defect Index Number

According to the definition of the GB defect index number described earlier, Figure 12 shows the change in the GB defect index number as a function of the heating temperature in air and cold rolling reduction ratio. Figure 13 shows the change in the GB defect index number with respect to the cold rolling reduction ratio, as a function of heating temperature in air and exposure to simulated PWR primary water with different hydrogen concentrations. Figure 14 shows the change in the GB defect index number as a function of the heating time at $673 \mathrm{~K}\left(400{ }^{\circ} \mathrm{C}\right)$ in air and cold rolling ratio.

From Figures 12 and 13, it is clear that the GB defect index number for cold rolled commercial TT Alloy 690 


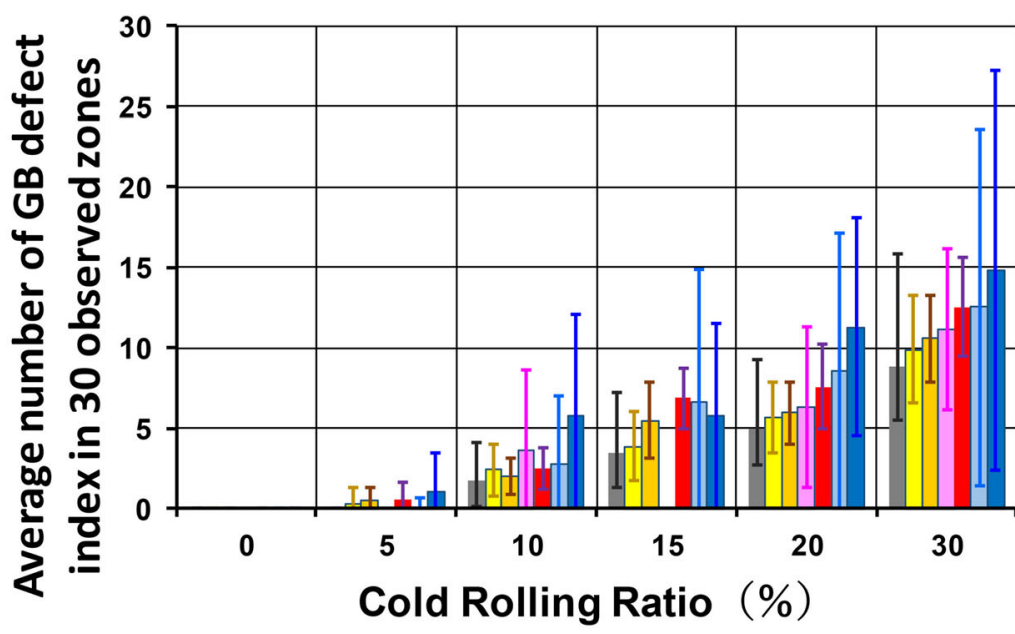

Size of cavity type : $A \leqq 25 \mathrm{~nm}, B \leqq 50 \mathrm{~nm}, C \leqq 100 \mathrm{~nm}, D \leqq 200 \mathrm{~nm}$

Width of crack type : $\alpha \leqq 25 \mathrm{~nm}, \beta \leqq 50 \mathrm{~nm}, Y \leqq 100 \mathrm{~nm}$

GB defect index $=A \times 1+B \times 3+C \times 5+D \times 7+\alpha \times 2+\beta \times 4+y \times 6$
Before Heating

$\square$ Heated at $633 \mathrm{~K}$ for 72.35

Ms in Air

$\square$ Heated at $673 \mathrm{~K}$ for 72.37 Ms in Air

$\square$ Heated at $693 \mathrm{~K}$ for $72.51 \mathrm{Ms}$ in Air

- Heated at $748 \mathrm{~K}$ for 22.83 Ms in Air

$\square$ Exposure in simulated PWR primary water with $5 \mathrm{cc} / \mathrm{kg}$ $\mathrm{H} 2$

Exposure in simulated PWR primary water with $50 \mathrm{cc} / \mathrm{kg}$ $\mathrm{H} 2$

Fig. 13 - Change in the average number of GB defect index in 30 observed zones with error bar of standard deviation as a function of the cold rolling reduction ratio, heating temperature in air and exposure in simulated PWR primary water with different hydrogen concentrations.

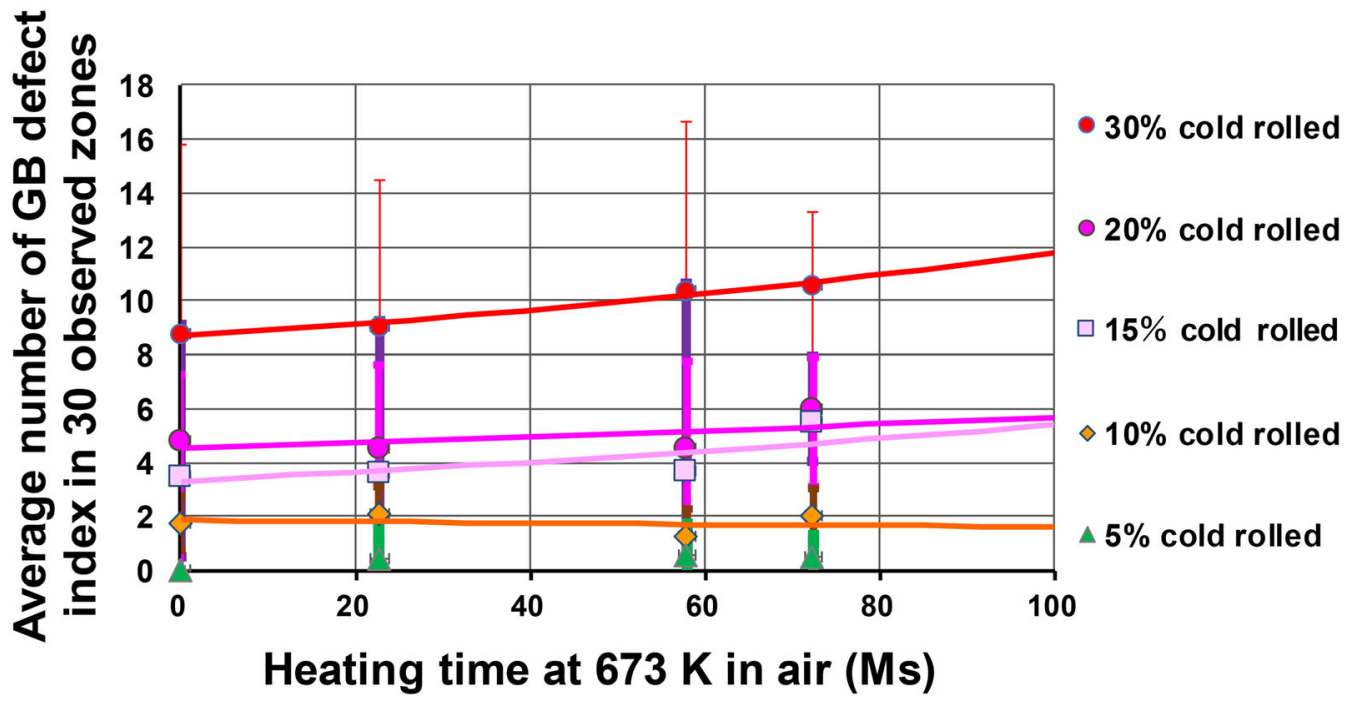

Fig. 14 Change in the average number of GB defect index in 30 observed zones with error bar of standard deviation as a function of heating time at $673 \mathrm{~K}$ in air and cold rolling reduction ratio.

increases with increasing cold rolling reduction ratio, heating temperature in air and hydrogen concentration in the simulated PWR primary water. From Figure 14, the effect of heating time at $673 \mathrm{~K}$ in air on the GB defect index number is not significant for cold rolled commercial TT Alloy 690 of $\leq 20$ pct. However, for 30 pct cold rolled commercial TT Alloy 690, the GB defect index number definitely increases with increasing heating time at $673 \mathrm{~K}$ in air. It is deduced that in case of the heavily cold worked (e.g. 30 pct cold rolled) commercial TT Alloy 690, too many voids and vacancies are generated near the GB carbides so that the sizes of cavities and cracks are enlarged by longer times heating in air. (in this paper, it was defined that the cavities were agglomerated voids, voids were agglomerated vacancies or lattice defects).

E. Correlation Between Vickers Hardness or GB DEFECT Index Number and Average SCCGR in Simulated PWR Primary Water for Cold Rolled Commercial TT Alloy 690 and the Possible Cracking Mechanism

In the authors' previous paper, ${ }^{[35]}$ it was deduced from TEM observations (as shown in Figure 15) that cavities at or near GB carbides in cold worked TT Alloy 690 are generated by shear strain due to heavy cold rolling. A high density of lattice defects is also observed 

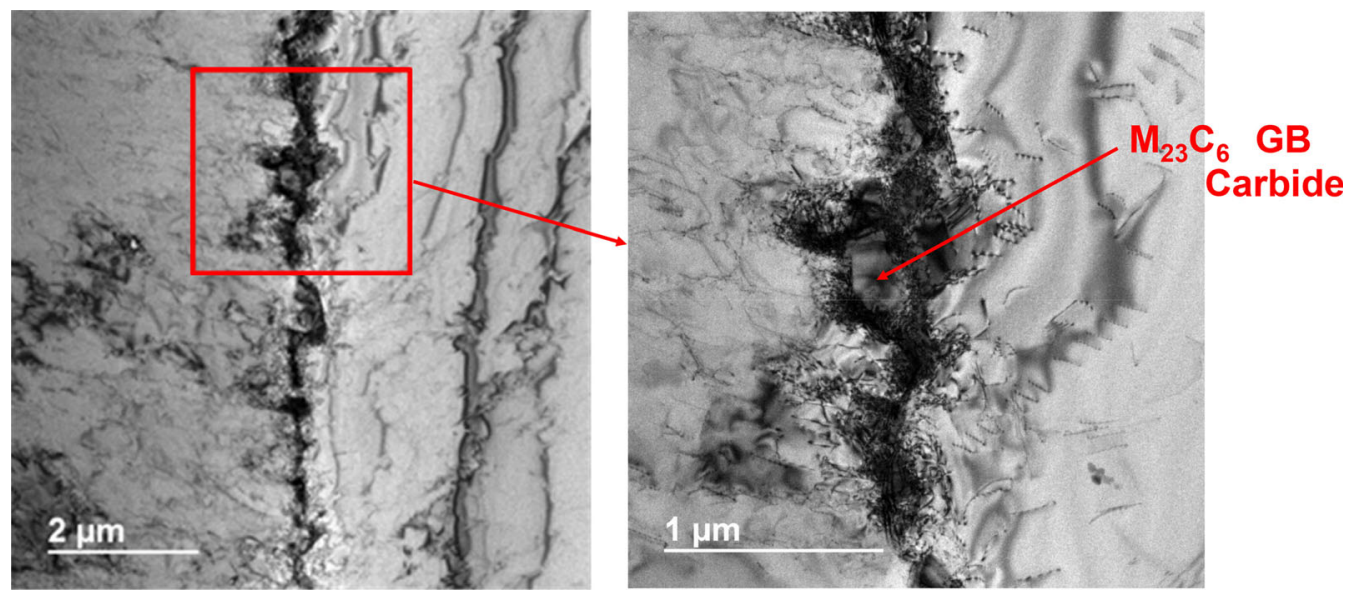

Fig. 15-Typical photos of dislocations near GB carbides in 5 pct cold rolled commercial TT Alloy 690 from a PWR CRDM nozzle.

\begin{tabular}{|c|c|c|c|c|c|}
\hline \multirow{2}{*}{ Original Material for Three Point Beam SCC Test Specimen } & \multirow{2}{*}{$\begin{array}{c}\text { No. of } \\
\text { Specimen }\end{array}$} & \multicolumn{4}{|c|}{ Hydrogen Content (ppm) } \\
\hline & & No.1 & No.2 & No.3 & Ave. \\
\hline As $30 \%$ CR Commercial TT Alloy 690 for CRDM Tube & S69-30-1 & 5.1 & 4.4 & 4.2 & 4.6 \\
\hline As $30 \%$ CR Commercial TT Alloy 690 for CRDM Tube & S69-30-2 & 2.5 & 2.3 & - & 2.4 \\
\hline As $30 \%$ CR Commercial TT Alloy 690 for CRDM Tube & N69-30-1 & 4.3 & 4.4 & - & 4.4 \\
\hline After Heated in Air at $633 \mathrm{~K}$ for $22.7 \mathrm{Ms}$ & S69-30-A & 0.4 & 0.2 & 0.4 & 0.3 \\
\hline After Exposure in Primary Water with $30 \mathrm{cc}$ Hydrogen at $633 \mathrm{~K}$ for $22.7 \mathrm{Ms}$ & $569-30-30$ & 1.4 & 1.3 & 1.8 & 1.5 \\
\hline After Exposure in Primary Water with $5 \mathrm{cc}$ Hydrogen at $633 \mathrm{~K}$ for $3.33 \mathrm{Ms}$ & S69-30-5 & 0.4 & 1 & 0.8 & 0.7 \\
\hline After Exposure in Primary Water with $50 \mathrm{cc}$ Hydrogen at $633 \mathrm{~K}$ for $3.33 \mathrm{Ms}$ & S69-30-50 & 1.7 & 1.9 & 1.5 & 1.7 \\
\hline
\end{tabular}

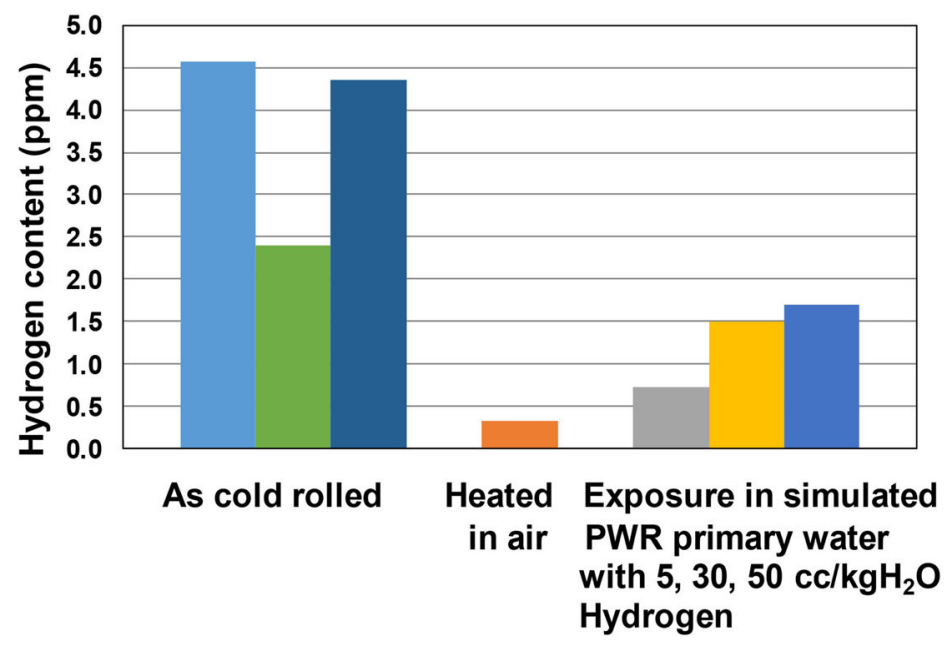

As Cold Rolled

As Cold Rolled

As Cold Rolled

After Heated in Air at $633 \mathrm{~K}$

After Exposure in Primary Water with $5 \mathrm{cc} / \mathrm{kg}$ Hydrogen

After Exposure in Primary Water with $30 \mathrm{cc} / \mathrm{kg}$ Hydrogen

After Exposure in Primary Water with $50 \mathrm{cc} / \mathrm{kg}$ Hydrogen

Hydrogen

Fig. 16-Effect of heating at $633 \mathrm{~K}$ in air or exposure in simulated PWR primary water at $633 \mathrm{~K}$ with different hydrogen concentrations on the Hydrogen contents of specimens of cold rolled commercial TT Alloy 690.

at or near GB carbides after cold rolling, which agglomeration of lattice defects or voids near GB carbides during heating at high temperatures where lattice defects are sufficiently mobile. So, the size of cavities increases and the width of cracks enlarge due to the agglomeration of lattice defects or voids. And then, the GB defect index number for cold rolled TT Alloy 690 without stress will be increased after heating in Air.
While, it was also deduced from the analysis of Hydrogen content in the test specimens as shown in Figure 16. The hydrogen contents in the test specimens as cold rolled condition were measured as 2 to $5 \mathrm{ppm}$ (as normal number of Ni base alloy), but mostly zero after heating in air (may be mostly baked out by heating in air), but the hydrogen content in the exposed specimens increased with increasing hydrogen content in the 


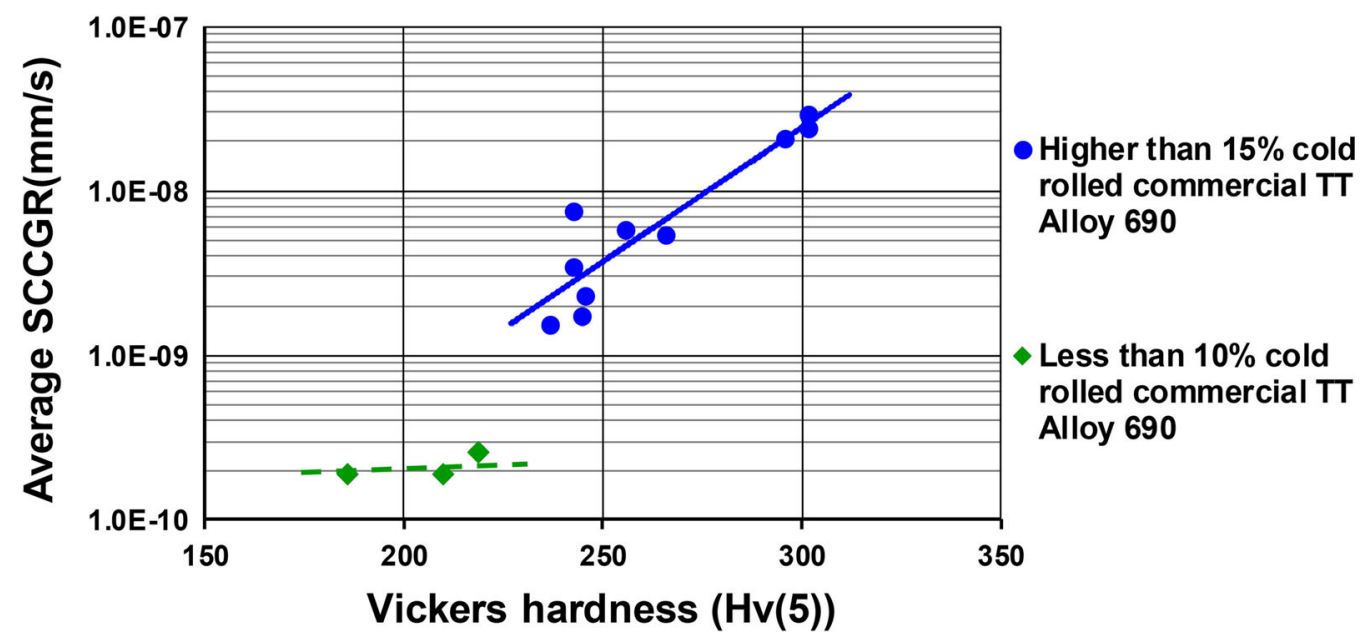

Fig. 17- Correlation between Vickers hardness and the averaged PWSCCGR at $633 \mathrm{~K}$ in simulated PWR primary water for $\geq 15$ pct cold rolled or $\leq 10$ pct cold rolled commercial TT Alloy 690 .

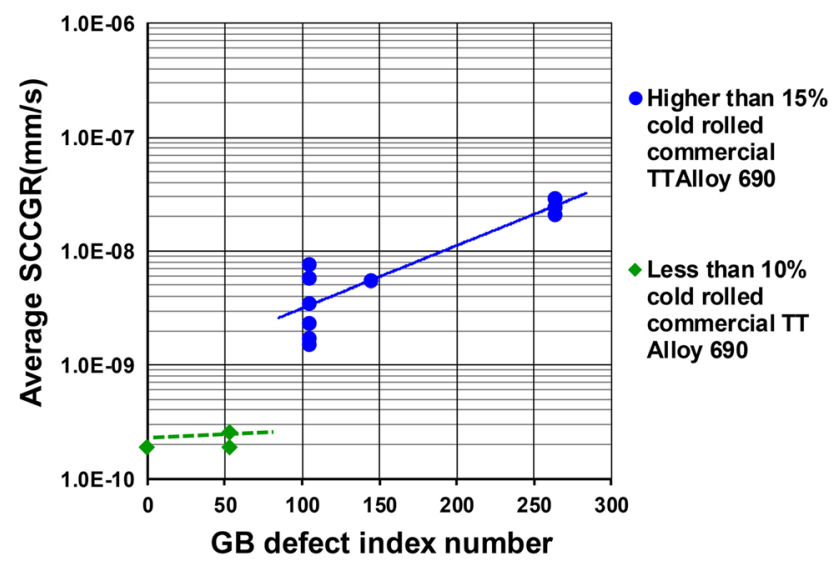

Fig. 18 - Correlation between the GB defect index number and the averaged PWSCCGR at $633 \mathrm{~K}$ in simulated PWR primary water for $\geq 15$ pet cold rolled or $\leq 10$ pet cold rolled commercial TT Alloy 690 .

simulated PWR primary water based on the solute hydrogen level in the simulated primary water. That is, the cavities could be stabilized by Hydrogen absorption from hydrogenated PWR primary water.

From Figures 15 and 16, the new cavities or coarse cavities can be generated by prolonged heating and also stabilized by absorbed Hydrogen.

Figure 17 shows a correlation between the Vickers hardness of cold rolled commercial TT Alloy 690 and the average PWSCCGR observed at $633 \mathrm{~K}$ in simulated PWR primary water. Figure 18 shows a correlation between the GB defect index number and the average PWSCCGR at $633 \mathrm{~K}$ in simulated PWR primary water for cold rolled commercial TT Alloy 690.

From these figures, it is clear that the average PWSCCGRs at $633 \mathrm{~K}$ in simulated PWR primary water for the higher than 15 pct cold rolled commercial TT Alloy 690 increase with increasing of Vickers hardness or the GB defect index number.
While the average PWSCCGR for the $\leq 10$ pct cold rolled commercial TT Alloy 690 does not increase despite increasing Vickers hardness or GB defect index number, it is considered that the generation of cavities at or near GB carbides is negligible for $\leq 10$ pct cold rolling (the likely upper limit of cold working level in practical components).

From these observations, it is concluded that the mechanism of SCCGR for the $\geq 15$ pct cold rolled commercial TT Alloy 690 could be different from that for $\leq 10$ pct cold rolled commercial TT Alloy 690 .

As described in the beginning of this paper, although the TT Alloy 690 has been used as actual PWR component materials for more than 30 years in the PWR primary water environment without any SCC indications in the world, some researchers reported that the PWSCCGRs of the TT Alloy 690 are relatively large in their testing.

But, based on the above, it is considered that the reason why their PWSCC data are very large is to using the heavily cold worked TT Alloy 690 in their tests, but the TT Alloy 690 in the actual PWR components is using relatively low or non-cold worked materials.

\section{CONCLUSIONS}

The objective of this study was to examine the possibility of a creep driven mechanism for PWSCC in heavily cold worked commercial TT Alloy 690. The stress dependency of the number, shape and size of cavities observed at or near GB carbides was evaluated using three point bent beam SCC specimens and reverse U-bend SCC specimens before and after long-term exposure at $633 \mathrm{~K}$ in simulated PWR primary water. In addition, the PWSCCGR in simulated PWR primary water and the number, shape and size of cavities observed at or near GB carbides close to and remote from growing crack tips in cold rolled commercial TT Alloy 690 were evaluated. The number, shape and size of cavities at or near GB carbides in specimens of the 
cold worked commercial TT Alloy 690 were also observed before and after long-term heating in air and before and after long-term exposure at $633 \mathrm{~K}$ in simulated PWR primary water.

From these studies, the following conclusions have been deduced.

1. In case of heating at 633 to $748 \mathrm{~K}$ for about $7.2 \mathrm{Ms}$ (2,000 hours), the number of the cavities at or near GB carbides in cold rolled commercial TT Alloy 690 increased with increasing cold rolling reduction ratio and heating temperature in air. However, after heating at 633 to $693 \mathrm{~K}$ during about $7.2 \mathrm{Ms}(2,000$ hours) or at $748 \mathrm{~K}$ for $22.82 \mathrm{Ms}(6,340$ hours) in air, it can no longer be claimed that only the number of the cavities at or near GB carbides in cold rolled commercial TT Alloy 690 increase with increasing heating temperature since not only the number of cavities, but also the shape and size of the cavities changed as a function of increasing temperature and time.

2. The shape of cavities observed in cold worked commercial TT Alloy 690 were categorized according to cavity and crack type, size, and numbers and a GB defect index has been defined on this basis.

3. No stress dependency was observed for the GB defect index number either for three-point bent beam SCC test specimens or reverse U-bend SCC test specimens. Therefore, the detected cavities at and near grain boundary carbides in heavily cold rolled commercial TT Alloy 690 after exposure in the simulated PWR primary water at $633 \mathrm{~K}$ are clearly not related to creep damage.

4. The GB defect index number for cold rolled commercial TT Alloy 690 increased with increasing cold rolling reduction ratio, heating temperature in air and hydrogen concentration in the simulated PWR primary water.

5. The average PWSCCGR for $\geq 15$ pct cold rolled commercial TT Alloy 690 increased with increasing Vickers hardness and GB defect index number. However, the average PWSCCGR for $\leq 10$ pct cold rolled commercial TT Alloy 690 did not increase in spite of increasing Vickers hardness or GB defect index number.

6. It is likely that the generation of cavities at or near GB carbides is negligible for $\leq 10$ pct cold rolling (the likely upper limit of cold work in practical components).

\section{ACKNOWLEDGMENTS}

This study was performed as a part of a collaborative research program that was financially supported by the Hokkaido Electric Power Company, the Kansai Electric Power Company, the Shikoku Electric Power Company, the Kyushu Electric Power Company and Mitsubishi Heavy Industries, Ltd. All of the test materials were supplied by the Nippon Steel corporation (formerly Sumitomo Metals). The authors would like to acknowledge their financial support. The authors also wish to greatly acknowledge Prof. Emeritus of Tohoku University, Dr. Tetsuo Shoji for his helpful suggestions, comments and discussions.

\section{OPEN ACCESS}

This article is licensed under a Creative Commons Attribution 4.0 International License, which permits use, sharing, adaptation, distribution and reproduction in any medium or format, as long as you give appropriate credit to the original author(s) and the source, provide a link to the Creative Commons licence, and indicate if changes were made. The images or other third party material in this article are included in the article's Creative Commons licence, unless indicated otherwise in a credit line to the material. If material is not included in the article's Creative Commons licence and your intended use is not permitted by statutory regulation or exceeds the permitted use, you will need to obtain permission directly from the copyright holder. To view a copy of this licence, visit http://creat ivecommons.org/licenses/by/4.0/.

\section{REFERENCES}

1. A.J. Sedriks, J.W. Schultz, and M.A. Cordovi: Boshoku Gijutsu, 1979, vol. 28, pp. 82-95.

2. T. Yonezawa, K. Onimura, N. Sasaguri, T. Kusakabe, H. Nagano, K. Yamanaka, T. Minami, and M. Inoue: Proceedings of the Second International Symposium on "Environmental Degradation of Materials in Nuclear Power Systems-water Reactors (Hereinafter abbreviated as "Proceedings of the 2nd ENVDEG") Monterey, CA, 9-12 September 1985, pp. 593-600.

3. T. Yonezawa, K. Onimura, N. Sasaguri, T. Kusakabe, H. Nagano, K. Yamanaka, T. Minami, and M. Inoue: "Effect of Heat Treatment on Corrosion Resistance of Alloy 690", in Proceedings of the International Symposium on Contribution of Materials Investigation to the Resolution of Problems Encountered in PWR Plants, Royal Abbey of Fontevraud (Hereinafter abbreviated as "Proceedings of the FONTEVRAUD"), France, 2-6 September 1985, pp. 289-96.

4. T. Yonezawa, N. Sasaguri, and K. Onimura: Proceedings of the 1988 JAIF International Conference on Water Chemistry in Nuclear Power Plants, Tokyo, Japan, 19-22 April 1988, pp. 490-95.

5. T. Kusakabe, T. Yonezawa, and S. Tokunaga: Research on Corrosion Resistance of Steam Generator Tube, Mitsubishi Heavy Industries, Ltd., Technical Review, 1996, vol. 33(1), pp. 1-5.

6. W. Bamford, A. Jenks, R. Janowiak, and G. Stevens: Proceedings of the 19th ENVDEG (2019), pp. 256-65.

7. G.P. Airley: Metallography, 1980, vol. 13, pp. 21-41.

8. T. Yonezawa, K. Onimura, N. Sakamoto, N. Sasaguri, H. Nakata, and H. Susukida: Proceedings of the 1st ENVDEG, Myrtle Beach, SC, 22-25 August 1983, pp. 345-66.

9. E.L. Hall and C.L. Briant: Metall. Mater. Trans. A, 1985, vol. 16A, pp. 1225-36.

10. S.M. Bruemmer, L.A. Charlot, and C.H. Henager, Jr.: Corrosion, 1988, vol. 44, pp. 782-88.

11. J.S.Fish, N.Lewis, W.J.S.Yang, D.J.Perry, and C.D.Thompson: Proceedings of the 8th ENVDEG, America Island, FLA, 10-14 August 1997, pp. 266-73.

12. R. Bandy and D.V. Rooyen: Nucl. Eng. Des., 1985, vol. 86, pp. 49-56.

13. N. Ogawa, T. Kohno, M. Yamada, R. Umehara, Y. Arimoto, S. Okamoto, and T. Tsuruta: Nucl. Eng. Des., 1996, vol. 165, pp. $171-80$. 
14. P.M. Scott and M. Le Calvar: Proceedings of the 6th ENVDEG, San Diego, CA, 1-5 August 1993, pp. 657-67.

15. P.M. Scott and P. Combrade: Proceedings of the 8th ENVDEG, America Island, FLA, 10-14 August 1997, pp. 65-73.

16. G.P. Airley: Proceedings of 1983 EPRI Workshop on Primary-Side Stress Corrosion Cracking of PWR Steam Generator Tubing; EPRI NP-5498, Project S303-5, 1983.

17. N. Totsuka, E. Lunarska, G. Cragnolino, and Z. SzklarskaSmialowska: Corrosion, 1987, vol. 43, pp. 505-14.

18. N. Tostuka and Z. Szklarska-Smialowska: Proceedings of the 3rd ENVDEG, TMS, 1988, pp. 691-96.

19. R.B. Rebak and Z. Szklarska-Smialowska: Corros. Sci., 1996, vol. 38 , pp. $971-88$.

20. T. Cassagne, B. Fleury, F. Vaillant, O. de Bouvier, and P. Combrade: Proceedings of the 8th ENVDEG -ANS, 1997, pp. 307-315.

21. R.C. Newman: Corrosion, 1994, vol. 50, pp. 682-86.

22. R.C. Newman and C. Healey: Corros. Sci., 2007, vol. 49, pp. $4040-50$.

23. P.M. Scott and M. Le Calvar: Proceedings of the 9th ENVDEG, TMS, 1993, pp. 657-67.

24. T.S. Gendron, P.M. Scott, S.M. Bruemmer, and L.E. Thomas: Proceedings of the Third International Steam Generator and Heat Exchanger Conference, vol. 2, CNS, 1998, pp. 5.18-35.

25. P.M. Scott: Proceedings of the 9th ENVDEG, TMS, 1999, pp. 3-14.

26. P.M. Scott and P. Combrade: J. Nucl. Mater., 2019, vol. 524, pp. 340-75.
27. D.J. Paraventi and W.C. Moshier: Proceedings of the Workshop on "Effects of Cold Work on Stress Corrosion Cracking of Materials in Water Cooled Nuclear Plants, Mississauga, Toronto, Canada, 3-8 June 2007, CD-Rom.

28. K. Arioka, T. Yamada, T. Miyamoto, and T. Terachi: Proceedings of the FONTEVRAUD 7, Avignon, France, 26-30 September 2010, CD-Rom.

29. T. Yonezawa, M. Watanabe, and A. Hashimoto: Metall. Mater. Trans. A, 2015, vol. 46A, pp. 2768-80.

30. K. Arioka, T. Miyamoto, T. Yamada, and T. Terachi: Proceedings of the 15th ENVDEG, Cheyenne Mountain Resort, Colorado Springs, CO, USA, 7-11 August 2011, pp. 55-69.

31. K. Arioka, T. Yamada, T. Miyamoto, and T. Terachi: Proceedings of the 17th ENVDEG, Ottawa, ON, Canada, 9-13 August 2015, CD-Rom.

32. S.M. Bruemmer, M.J. Olszta, N.R. Overman, and M.B. Toloczko: Proceedings of the 17th ENVDEG, 2015, CD-Rom.

33. Z. Zhai, M. Toloczko, K. Kruska, D. Schreiber, and S. Bruemmer: Proceedings of the 18th ENVDEG, 2017, pp. 457-83.

34. M. Olszta, Z. Zhai, M. Toloczko, and S. Bruemmer: Proceedings of the 19th ENVDEG, 2019, pp. 274-85.

35. T. Yonezawa, M. Watanabe, and A. Hashimoto: Proceedings of the 19th ENVDEG, 2019, pp. 245-55.

36. ISO/TC $156 \mathrm{~N} 1172$.

Publisher's Note Springer Nature remains neutral with regard to jurisdictional claims in published maps and institutional affiliations. 